\title{
Utilização de copos plásticos descartáveis na composição do traço para a produção de
}

\section{tijolo ecológico}

Use of disposable plastic cups in the composition of the mix for the production of ecological brick Uso de vasos de plástico desechables en la composición de la mezcla para la producción de ladrillo ecológico

Paulysendra Felipe Silva

ORCID: https://orcid.org/0000-0002-0129-8772 Instituto Federal de Educação, Ciência e Tecnologia do Piauí, Brasil

E-mail: sendra_102@hotmail.com

Rebeka Manuela Lobo Sousa

ORCID: https://orcid.org/0000-0002-8195-6447 Instituto Federal de Educação, Ciência e Tecnologia do Piauí, Brasil E-mail:rebekamanuela28@gmail.com

Francisca das Chagas Oliveira

ORCID: https://orcid.org/0000-0002-6262-9125 Instituto Federal de Educação, Ciência e Tecnologia do Piauí, Brasil E-mail: francisca.mat@hotmail.com

Heitor Fernandes Sousa

ORCID: https://orcid.org/0000-0002-7617-4117 Instituto Federal de Educação, Ciência e Tecnologia do Piauí, Brasil E-mail: heitorfcivil@gmail.com

Phillype Dowglas Lopes

ORCID: https://orcid.org/0000-0002-4103-3883 Instituto Federal de Educação, Ciência e Tecnologia do Piauí, Brasil

E-mail: eng.phillype@hotmail.com

Francisco Arlon De Oliveira Chaves ORCID: https://orcid.org/0000-0002-5503-0923 Centro Universitário Santo Agostinho E-mail: arlonoliv@hotmail.com

Linardy de Moura Sousa

ORCID: https://orcid.org/0000-0002-3396-8080 Centro Universitário Santo Agostinho E-mail: linardy_moura@hotmail.com

Gilvan Moreira da Paz

ORCID: https://orcid.org/0000-0002-6849-0320 Instituto Federal de Educação, Ciência e Tecnologia do Piauí, Brasil E-mail:gilvan@ifpi.edu.br

Roberto Arruda Lima Soares

ORCID: https://orcid.org/0000-0003-1892-7499

Instituto Federal de Educação, Ciência e Tecnologia do Piauí, Brasil

E-mail: robertoarruda@ifpi.edu.br

\begin{abstract}
Resumo
Diante do crescimento dos impactos ambientais no mundo, estamos buscando e aprimorando materiais sustentáveis para uso na construção civil. Dentre os materiais temos o tijolo ecológico, que reduz a poluição desde o processo de fabricação, pois não precisa ser queimado, não é necessário alimentar os fornos evitando o desmatamento. É composto por areia, cimento e água. A construção feita com este tijolo apresenta temperaturas no interior agradáveis, suportando muito bem as altas temperaturas. O presente trabalho visa adicionar copos descartáveis triturados visando melhorar as características e propriedades do tijolo ecológico, onde serão moldados corpos de prova para obtenção dos resultados.Os tijolos ecológicos com porcentagens de 0\%, 40\% e 60\% de copos descartáveis triturados foram submetidos aos testes de resistência à compressão e absorção de água. Após a realização dos ensaios mecânicos e caracterização do material nos laboratórios da UNIFSA e PPGEM, observou-se que é possível utilizar copos descartáveis triturados como componente do tijolo ecológico ainda de acordo com os resultados obtidos, apenas a formulação com 40\% de adição de copos atende aos requisitos das normas NBR8491 / 12 e NBR8492 / 12.
\end{abstract}

Palavras-chave: Sustentabilidade; Copos de plástico; Tijolo Ecológico. 


\begin{abstract}
Faced with the growth of environmental impacts in the world we are seeking and improving sustainable materials for use in civil construction. Among the materials we have the ecological brick, this reduces pollution since the manufacturing process, because it does not need burning, it is not necessary to feed the ovens by avoiding deforestation. It consists of sand, cement and water. The construction made with this brick presents pleasant temperatures inside, very well supporting the high temperatures. The present work aims to add crushed disposable cups aiming at improving the characteristics and properties of the ecological brick, where specimens will be molded to obtain the results. The ecological bricks with $0 \%, 40 \%$ and $60 \%$ percentages of crushed disposable cups were submitted to tests of compressive strength and water absorption. After performing the mechanical tests and characterization of the material in the laboratories of UNIFSA and PPGEM, it was observed that it is possible to use crushed disposable cups as a component for the ecological brick still according to the results obtained, only the formulation with $40 \%$ of cups addition meets the requirements set out in the NBR8491/12 standards and in NBR8492/12.
\end{abstract}

Keywords: Sustainability; Plastic Cups; Ecological Brick.

\title{
Resumen
}

Dado el crecimiento de los impactos ambientales en el mundo, buscamos y mejoramos materiales sostenibles para su uso en la construcción civil. Entre los materiales tenemos el ladrillo ecológico, que reduce la contaminación del proceso de fabricación, ya que no necesita ser quemado, no es necesario alimentar los hornos, evitando la deforestación. Consiste en arena, cemento y agua. La construcción realizada con este ladrillo tiene temperaturas agradables en su interior, soportando muy bien las altas temperaturas. El presente trabajo tiene como objetivo sumar vasos desechables triturados con el fin de mejorar las características y propiedades del ladrillo ecológico, donde se moldearán los ejemplares para obtener los resultados. Los ladrillos ecológicos con porcentajes de $0 \%$, 40\% y $60 \%$ de vasos desechables triturados fueron sometidos a pruebas de resistencia a la compresión y absorción de agua. Luego de realizar las pruebas mecánicas y caracterización del material en los laboratorios de UNIFSA y PPGEM, se observó que es posible utilizar vasos desechables triturados como componente del ladrillo ecológico, aún de acuerdo a los resultados obtenidos, solo la formulación con $40 \%$ La adición de copas cumple con los requisitos de las normas NBR8491 / 12 y NBR8492 / 12.

Palabras clave: Sustentabilidad; Copas de plástico; Ladrillo ecológico.

\section{Introdução}

O setor de construção civil é o que mais se utiliza de recursos naturais para sua execução Silva et al., (2018). Sendo assim, torna-se indispensável buscar novas soluções tecnológicas que permitam um manejo ecológico, possibilitando cuidar cada vez mais do meio ambiente. Incorporar novas tecnologias e materiais na construção civil, possibilitam muitas vezes diminuir os impactos gerados pelas construções e possivelmente baixar seu custo final. Importante considerar a perspectiva econômica, pois a disposição desses resíduos em aterros gera altos custos, tornando a reciclagem uma opção mais atrativa. Outro fator de relevância econômica é a minimização da compra de novos materiais, uma vez que há a substituição desses materiais pelos resíduos, gerando a redução dos custos de aquisição de matéria prima (Matuti \& Santana, 2019).

As principais vantagens da reciclagem são, os altos preços para deposição de resíduos em aterros, tornam a reciclagem mais atrativa do ponto de vista financeiro para os geradores de resíduos, a reciclagem reduz o volume de extração de matériasprimas, minimizando os impactos gerados pela extração, a produção de materiais reciclados, redução da poluição, a incorporação de resíduos permite a produção de materiais de melhor qualidade, a reciclagem promove a redução de aterros e, consequentemente, a contaminação ambiental, problemas de saneamento público e custos sociais no gerenciamento de resíduos (Zorzeto, 2017).

A maioria dos artigos plásticos vendidos, especialmente as embalagens e outros bens não-duráveis, torna-se resíduo em menos de um ano, ou, no pior cenário, após um único uso. Ainda assim, os resíduos plásticos são valorosas fontes de matérias-primas, e podem ser transformados em energia ou em outros materiais poliméricos (Al-Salem et al.,2009).

O descarte incorreto acaba sendo comum no Brasil, e as principais razões são a falta de coleta de lixo, especialmente em comunidades mais pobres, e o péssimo hábito brasileiro de jogar lixo no chão, nas ruas e nos corpos d'água (Coelho et 
al.,2001). Os plásticos podem causar muitos danos ao ambiente, pois demoram cerca de centenas de anos para se desfazerem (Quadro 1), trazendo muitos problemas para as pessoas e o meio ambiente (Gorni,2003).

Quadro 1: Decomposição dos materiais

\begin{tabular}{|l|c|}
\hline \multicolumn{1}{|c|}{ Materiais } & Decomposição \\
\hline Um simples chiclete & 5 anos \\
\hline Restos orgânicos & 2 a 12 meses \\
\hline Lata de aço & 10 anos \\
\hline Embalagem longa vida & 100 anos \\
\hline Garrafa de Vidro & 10.000 anos \\
\hline Sacos e copos plásticos & 200 a 450 anos \\
\hline Papel ou um cigarro & 3 meses a vários anos \\
\hline Madeira & 1 ano \\
\hline Lata de alumínio & 1000 anos \\
\hline Nylon & 30 a 40 anos \\
\hline Pilhas & 100 a 500 anos \\
\hline
\end{tabular}

Fonte: Média de dados do CEMPRE e da Plastivida.

Uma forma de reduzir os impactos causados pela produção de plásticos seria reciclá-lo, pois reciclar é mais do que reaproveitar o material. Reciclar também economiza recursos energéticos e naturais gerando ganhos financeiros e ambientais (Gorni,2003).

Um grande benefício de se utilizar o tijolo ecológico, é a vantagem de permitir reutilizar recursos que, até então, seriam considerados como simples entulho, mas que, com a reutilização dos mesmos, se tornam parte importante da composição (Pedroti,2007).

Os tijolos ecológicos ou de solo-cimento são considerados tijolos de baixo custo (Penha et al., 2007). São uma mistura homogênea de: solo, cimento e água, compactados, com objetivo de amenizar a degradação do meio ambiente através da extração de matérias primas, sem alterar suas propriedades e seguindo as normas vigentes. Nessa perspectiva, devido à grande demanda do uso de matéria prima, a indústria da construção civil torna-se também a grande precursora para a reutilização de resíduos, e desse modo através da reciclagem dispor de agregados reciclados com um menor valor e reinseri-lo no mercado (Santos, 2012).

O tijolo ecológico possibilita a geração de menos resíduos no decorrer da obra e na economia de material em função da ausência de madeira para a produção das fôrmas da viga e do pilar, promovendo, assim, um isolamento acústico em razão dos furos em seu interior, redução do acúmulo de umidade, isolamento térmico, facilidade na instalação elétrica e hidráulica, uma vez que ambas podem ser feitas por meio dos furos do próprio tijolo, entre outros benefícios (Santos et al., 2009).

Verifica-se o tijolo ecológico que admite a reciclagem de resíduos, permitindo desta forma à minimização dos descartes e o aproveitamento dos resíduos como insumo de novos produtos, visando à economia de matérias-primas não renováveis, a diminuição da emissão de poluentes, melhoria nas condições de saúde, segurança e moradia da população (Campos,2007).

Este trabalho busca por alternativas que minimizem as agressões ao meio ambiente provocada pelo descarte de plásticos, visando proporcionar soluções ecologicamente corretas caracterizando e avaliando o grau de confiabilidade dos 
materiais utilizados na produção de tijolos de solo-cimento por meio de ensaios físicos, análise química, absorção de água e compressão simples.

\section{Revisão Bibliográfica}

\subsection{Plástico (Poliestireno - PS)}

Os plásticos são importantes na indústria e na sociedade. Eles aparecem nas mais diversas aplicações, desde produtos médico hospitalares e embalagens até peças de alta tecnologia, como as usadas em equipamentos espaciais (Sardella,2003). A sua multifuncionalidade e praticidade contribuiu para o aumento da sua demanda. Apresentam excelentes propriedades, são duráveis, leves, com resistência a corrosão e, principalmente, são baratos (Cunha, 2018 \& Geyer et al.,2017).

O poliestireno (PS) pertence ao grupo das resinas termoplásticas, que inclui, entre outros, os polietilenos (de alta densidade; baixa densidade; e baixa densidade linear), o polipropileno (PP), o cloreto de polivinila (PVC) e o polietileno tereftalato (PET). O PS é um plástico versátil que pode ser produzido na forma rígida ou na forma de espuma. Os usos mais comuns do PS rígido incluem embalagens de iogurte, cones para gelado, tabuleiros de comida rápida, talheres descartáveis, caixas de vídeos e brinquedos frágeis de baixo custo. O PS expandido (EPS) tem como propriedades gerais a baixa densidade aparente, por se encontrar na forma de espuma, a dureza, o excelente isolamento térmico, a capacidade de absorver o impacto, sendo, no entanto, susceptível à ação de gorduras e solventes (Charles \& Edward,2003).

No Brasil, em 2016, cerca de 8.000 toneladas mensais, um número que equivalente a 96.000 t/ano de copos descartáveis de poliestireno. Segundo os dados do setor, antes da edição da norma de padronização do referido produto, a produção nacional era de 6.000t/mês, valor significativo para se observar o número de copos que são descartados, muitos sem qualquer tratamento, despejados no ambiente (Gavião,2017). No uso de copos de plástico, deve-se levar em consideração que este material é produzido a partir de processos químicos no petróleo (poliestireno), que é uma fonte não renovável, poluente, e que implica grande impacto ambiental. Apesar de poder ser reciclado, é praticamente mínima a participação do poliestireno reciclado na produção de copos novos. Em virtude disso, nota-se que o produto descartável utiliza uma matéria-prima extrativa e não sustentável (Corrêa \& Heemann,2016).

\subsection{Reciclagem}

A conscientização ambiental está ocorrendo de forma lenta e progressiva, como forma de alcançar as melhorias na qualidade de vida nos seus mais diversos campos de atuação, assim, vem trazendo consigo uma cobrança maior para as empresas em fazer sua contribuição ambiental, para assim, não causar prejuízos e para que possa utilizar recursos naturais com maior racionalização e responsabilidade (Barsano \& Barbosa,2013). O consumo exacerbado de embalagens e outros produtos que integram plásticos na sua composição tem atingido valores demasiado preocupantes. Surgiu então abordagem dos 3R's, que abarca as três principais ações a aplicar de forma a controlar a produção de resíduos, esta política pressupõe 3 vagas de ação distintas: Reduzir, Reutilizar e Reciclar (Stevens,2002).

A reciclagem no Brasil é um ramo que ainda pode ser muito explorado por empresários, e infelizmente a falta de investimento nessa indústria acaba encarecendo o produto, devido à baixa oferta. Outro fator que pode prejudicar a indústria da reciclagem é a queda do preço do barril de petróleo, tornando o plástico reciclado menos interessante, devido à menor qualidade. A logística inversa da reciclagem também é um desafio a ser superado no Brasil, em grande parte devido à dispersão dos materiais pós-consumo (Tempo,2017).

De acordo com o Compromisso Empresarial Para Reciclagem CEMPRE, (2015) os plásticos representam cerca de 13,5\% dos resíduos sólidos urbanos no Brasil conforme Figura 1. 
Figura 1 - Infográfico representando a composição dos resíduos gerados no Brasil.

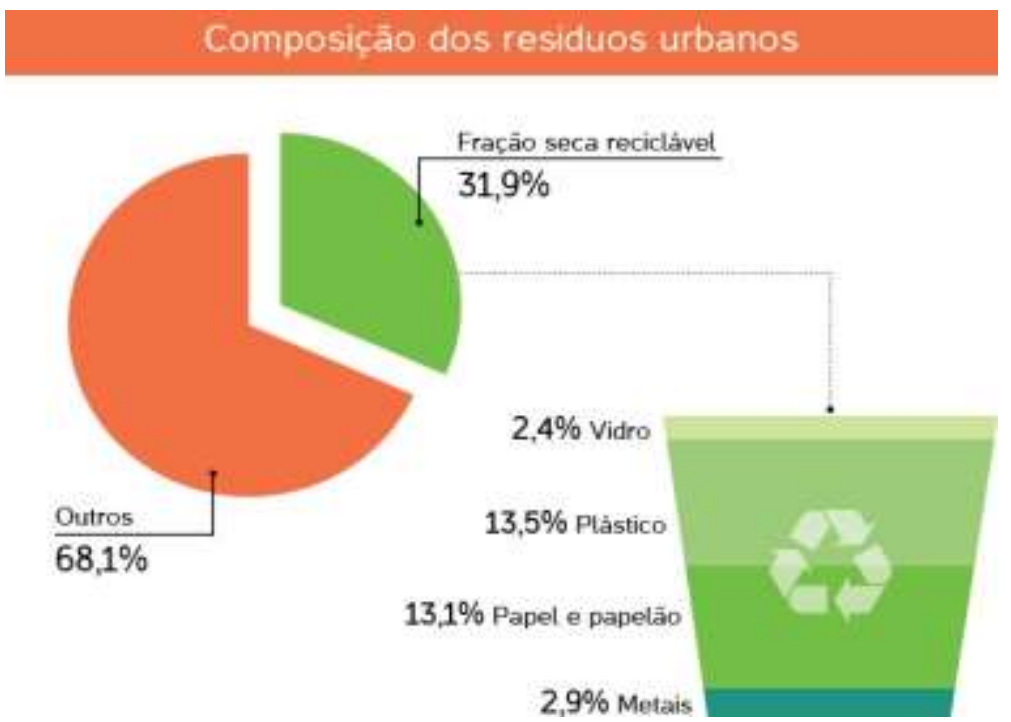

Fonte: CEMPRE (2017).

A reciclagem, evita a poluição do ambiente provocada pelo lixo, aumenta a vida útil dos aterros sanitários, diminuindo, a quantidade de resíduos sólidos, e também diminui a exploração dos recursos naturais, o qual não são renováveis como o petróleo (Cuccato,2014). O principal mercado consumidor de plástico reciclado na forma de grânulos são as indústrias de artefatos plásticos, que utilizam o material na produção de baldes, cabides, garrafas de água sanitária, conduítes e acessórios para automóveis, entre outros (Forlin \& Faria,2002 \& Alves,2018).

\subsection{Adições de materiais reciclados no tijolo ecológico}

Dentre os materiais derivados da reciclagem usados como adição em tijolos de solo-cimento (Figura 2) com o intuito de reforçar esse material, encontra-se a borracha de pneu (Figura 3) gerada principalmente no processo de recauchutagem, a dição de PET triturado, adição de resíduos de demolição entre outros.

Com adição de resíduos de pneus em seus estudos Gomes, (2018) concluiu que o tijolo de solo-cimento com adição de resíduo de borracha de pneu, constitui uma alternativa viável técnica e economicamente para a auxiliar na redução do déficit habitacional no Brasil e, em especial, na região Nordeste, por possuir um clima propicio para esse método construtivo. Além disso, vale lembrar que, a utilização desse resíduo é mais uma alternativapara diminuir a problemática do prejuízo ambiental, ocasionado pelo descarte inadequado do mesmo (Gomes,2018). 
Figura 2 - Corpos-de-prova com resíduo de pneu.

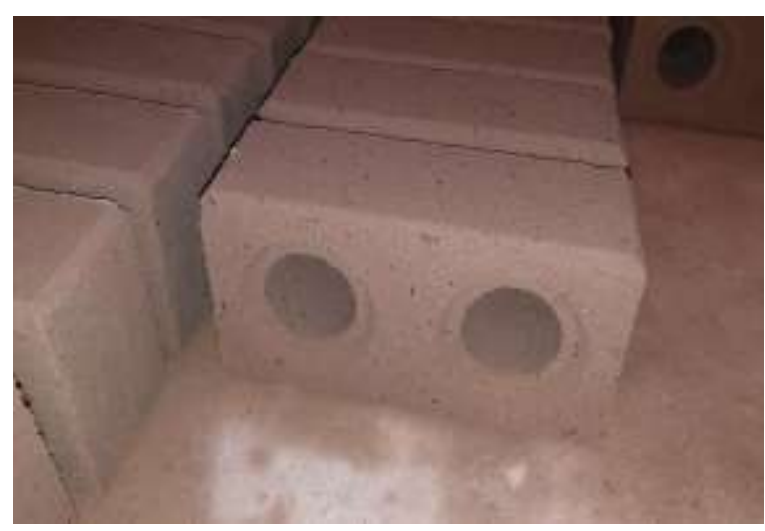

Fonte: Gomes, (2018)
Figura-3 Resíduos de borracha de pneus.

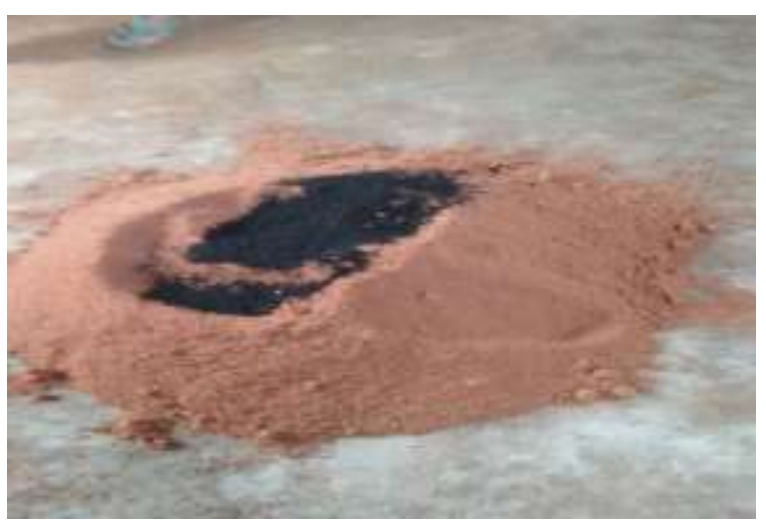

Fonte: Gomes, (2018)

Dentre as características mecânicas, destaca-se a resistência à compressão que apresentou grande aumento em relação aos tijolos de solo-cimento padrão. A borracha de pneu é um material viável em obras de engenharia, pois reduz o peso próprio do tijolo e também é ecologicamente correto, tirando da natureza resíduos que poderiam poluir o meio ambiente Bandeira, (2016). Outra adição à tijolos de solo-cimento frequentemente utilizada é a adição de residuos de PET (Figura 4), (Sena et al.,2017) concluiram que a incorporação de teores de resíduos de PET em substituição ao solo na produção de tijolos solocimento se mostrou satisfatória uma vez que os resultados dos traços avaliados atenderam as normas vigentes, mesmo com o procedimento adaptado de prensagem (Sena et al.,2017). Todos os traços contendo o resíduo apresentaram resistência mecânica a compressão média superior ao traço padrão, sendo que o maior valor encontrado foi quando o percentual de substituição foi $11 \%$.

Figura 4 - Resíduo de PET bruto.

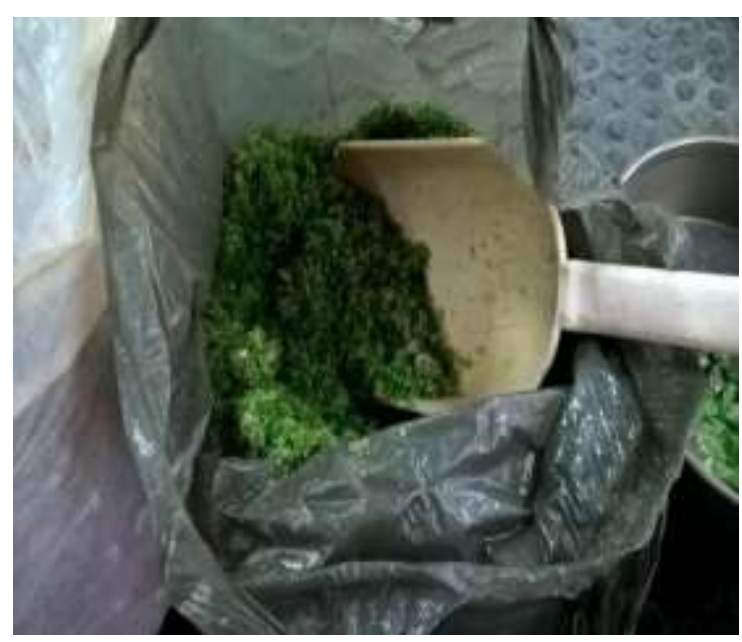

Fonte: Sena et al,(2017). 
Figura 5 - (A) colher utilizada para cada camada; (B) diâmetro interno soquete coincide com odiâmetro do CP e (C) soquete encaixado no CP.
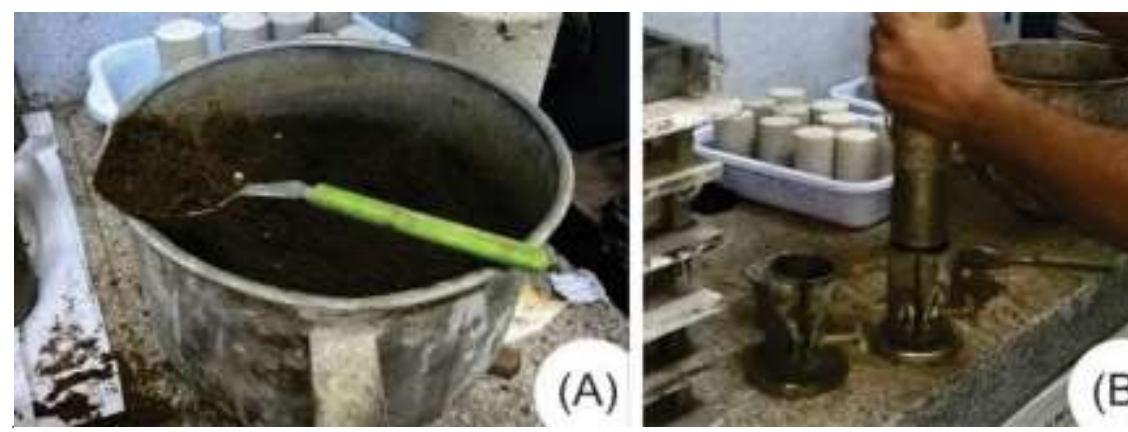

Fonte: Sena et al. (2017).

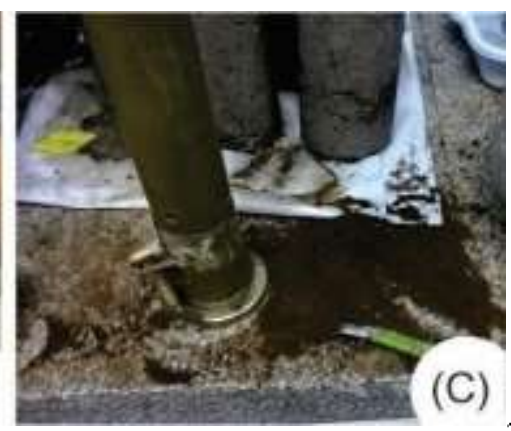

De acordo com Sena et al.,(2017), a substituição parcial do solo pelos resíduos PET possibilita a obtenção de produtos com propriedades técnicas que se enquadram nas especificações de normas para tijolo do tipo solo-cimento, onde a resistência mínima à compressão média e individual de 2,0MPa e 1,7MPa, respectivamente, a saber que o método de prensagem dos CP'S deste estudo foi realizado com um método adaptado apresentado na Figura 5 (A, B e C).

No trabalho desenvolvido Pinto, (2015) utilizou-se Residuos de construção civil (RCC) na composição de tijolo solocimento (Figuras 6 e 7) com seus respectivos traços: 1:8 e 1:10 de cimento e solo (solo e RCC em \%), as misturas obtidas foram as seguintes: M1a - correspondente ao traço de cimento da mistura: 1:8 e correspondente a mistura com 66,7\% de solo e 33,3\% de RCC; M2a - correspondente ao traço de cimento da mistura: 1:8 e correspondente a mistura com 50\% de solo e 50\% de RCC; M3a - correspondente ao traço de cimento da mistura: 1:8 e correspondente a mistura com 33,3\% de solo e $66,7 \%$ de RCC; M1b - correspondente ao traço de cimento da mistura: 1:10 e correspondente a mistura com 66,7\% de solo e 33,3\% de RCC; M2b - correspondente ao traço de cimento da mistura: 1:10 e correspondente a mistura com 50\% de solo e 50\% de RCC; M3b - correspondente ao traço de cimento da mistura: 1:10 e correspondente a mistura com 33,3\% de solo e $66,7 \%$ de RCC.

Figura 6- Máquina para Fabricação de Tijolos.

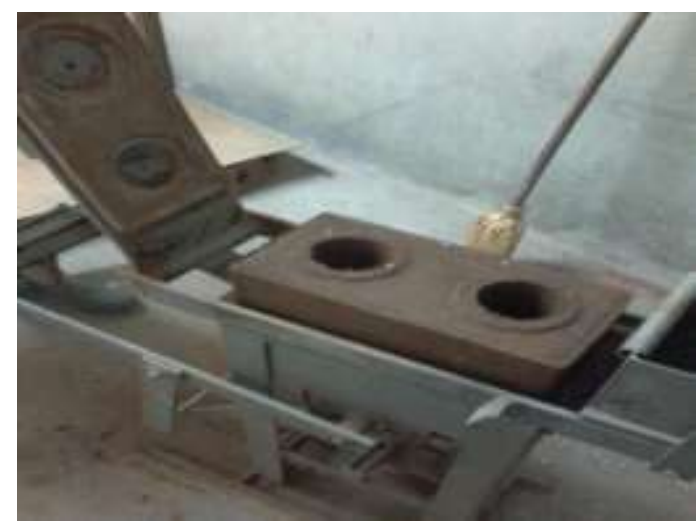

Fonte: Pinto (2015).
Figura 7 - Máquina Universal.

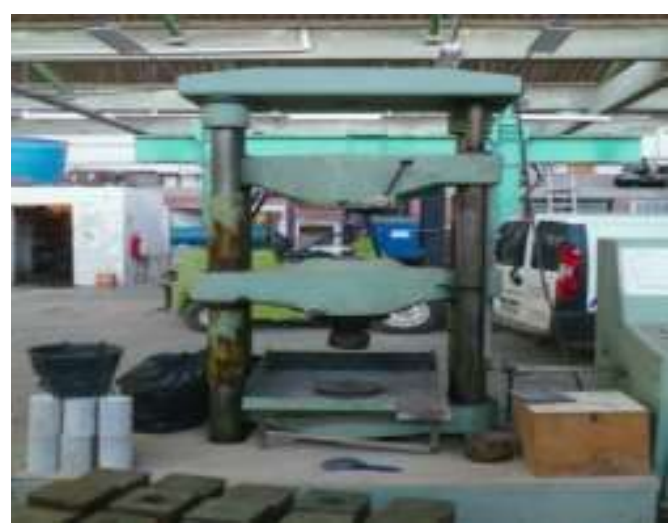

Fonte: Pinto (2015). 
De acordo Pinto, (2015) os resultados encontrados nos ensaios de compressão simples mostram que dentre todas as composições estudadas, apenas a M2b, aos 7 dias, e a M1b e M3a aos 28 dias tiverem valores de resistência à compressão simples superiores aos exigidos pela norma NBR 10836/13.

Quadro 2 - Comparativo do aumento da resistência à compressão entre 7 e 28 dias.

\begin{tabular}{|c|c|c|c|}
\hline \multirow{2}{*}{ Mistura } & \multicolumn{2}{|c|}{ Resistência à compressão simples (Mpa) } & \multirow{2}{*}{$\begin{array}{c}\text { Ganho de Resistência } \\
\text { (\%) }\end{array}$} \\
\cline { 2 - 3 } & $\mathbf{7}$ dias & $\mathbf{2 8 ~ d i a s}$ & 5,25 \\
\hline M1a & 1,03 & 1,09 & 54,17 \\
\hline M1b & 0,96 & 1,48 & 20,14 \\
\hline M2a & 1,72 & 2,06 & - \\
\hline M2b & 2,01 & 1,44 & 55,60 \\
\hline M3a & 1,47 & 2,29 & \\
\hline
\end{tabular}

Fonte: Pinto (2015).

Dentre todas as composições (Quadro 2) a que teve melhores resultados de resistência à compressão foi a que apresenta 33,3\% de solo e 66,67\% de RCC. Portanto, pode-se dizer que a fabricação de tijolos de solo-cimento com adição de quantidades de RCC é viável (Pinto,2015).

\section{Metodologia}

A pesquisa de campo é uma fase que é realizada após o estudo bibliográfico, para que o pesquisador tenha um bom conhecimento sobre o assunto (Marconi \& Lakatos, 2016). Este estudo apresenta a viabilidade da adição de copos descartáveis triturados em diferentes porcentagens para compor o processo de produção de tijolo ecológico. Os experimentos agora expostos foram elaborados no laboratório de Ciências dos Materiais do IFPI-PPGEM e no Laboratório de solos da UNIFSA. O período de desenvolvimento deste estudo compreende-se entre agosto de 2020 a março de 2021.

\subsection{Caracterização das matérias-primas}

A primeira etapa deste estudo concentra-se na caracterização da matéria-prima utilizada para a confecção do tijolo de solo-cimento, com o objetivo de identificar e classificar esse material para produção dos corpos de prova. Utilizou-se a argila proveniente da Jazida localizada na Estrada da Alegria-Teresina-PI. A argila passou pelo ensaio do vidro proposto por Taveira (1987) e pelo CEPED (1999). Continuando a preparação da amostra (Argila) para os ensaios de caracterização foi realizada conforme prescrições de materiais e métodos das normas citadas: Determinação do Limite de Liquidez (NBR 6459) e do Limite de Plasticidade (NBR 7180) - esses dois ensaios caracterizam o solo quanto aos índices básicos representativos da plasticidade; Granulometria por peneiramento e sedimentação (NBR 7181) - esse ensaio determina a distribuição granulométrica do solo e o FRX - ensaio químico que permite a observação de substâncias em estados diversos como gases, soluções, plasma e líquidos (Stuart,2004).

A segunda etapa deste estudo consistiu na coleta e caracterização dos copos descartáveis. A coleta desse material realizou-se entre dezembro a janeiro de 2019 em um prédio onde funciona a sede do DTRAN-PI sede em Teresina-PI, e devido a pandemia os ensaios só foram iniciados em agosto de 2020. Após a coleta do material, os copos descartáveis levados até os laboratórios do PPGEM, onde inicialmente passaram por um processo de limpeza em seguida quebrados em uma forrageira e triturados em um multiprocessador industrial e logo após para sua caracterização granulométrica e química, através de ensaio 
peneiramento e da técnica de FRX, respectivamente. Nestes ensaios, procedeu-se da mesma forma adotada para caracterizar a argila.

\subsection{Processo de produção do tijolo ecológico com adição de copos descartáveis triturados}

\subsubsection{Preparação dos traços}

O processo de amassamento deve ser realizado até que toda sua massa esteja totalmente homogênea, a fim de atestar que todo o seu volume esteja com propriedades iguais (ABNT, 2012). O traço utilizado para a produção do tijolo ecológico com adição de copos descartáveis triturados (Figura 8) foram de 1:10 (cimento + argila) e adicionou-se 80g (40\%) de copos descartáveis triturados para o primeiro traço, no segundo traço $120 \mathrm{~g}(60 \%)$ de copos descartáveis triturados e o terceiro traço com $0 \%$ de adição.

Figura 8 - Homogeneização do solo, cimento e copos descartáveis triturados.

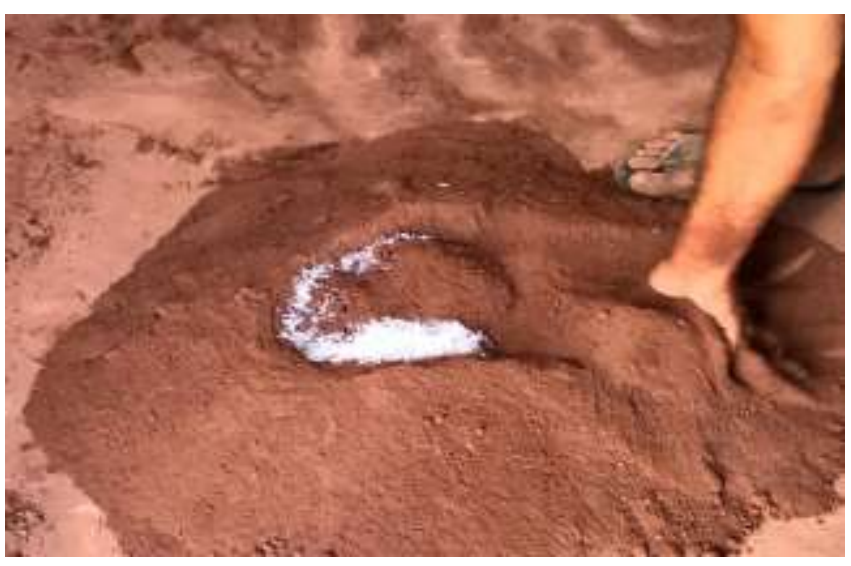

Fonte: Autor (2021).

\subsubsection{Prensagem do tijolo ecológico com copos triturados}

$\mathrm{Na}$ moldagem, transferir, imediatamente, a mistura para o molde e executar a prensagem, logo após, retira-los e empilha-los, à sombra, sobre uma superfície plana e lisa. (ABNT, 2012). A confecção dos corpos de provas foi baseada de acordo com a NBR 10833. A massa foi transferida para a máquina de prensa hidráulica (Figura 9), com pressão de 150 $\mathrm{kgf} / \mathrm{cm}^{2}$, dessa forma foram confeccionados 7 tijolos para cada traça citado anteriormente. Sendo 4 para o ensaio de compressão simples e 3 para o ensaio de absorção.

Figura 9 - Prensagem dos corpos de prova. 


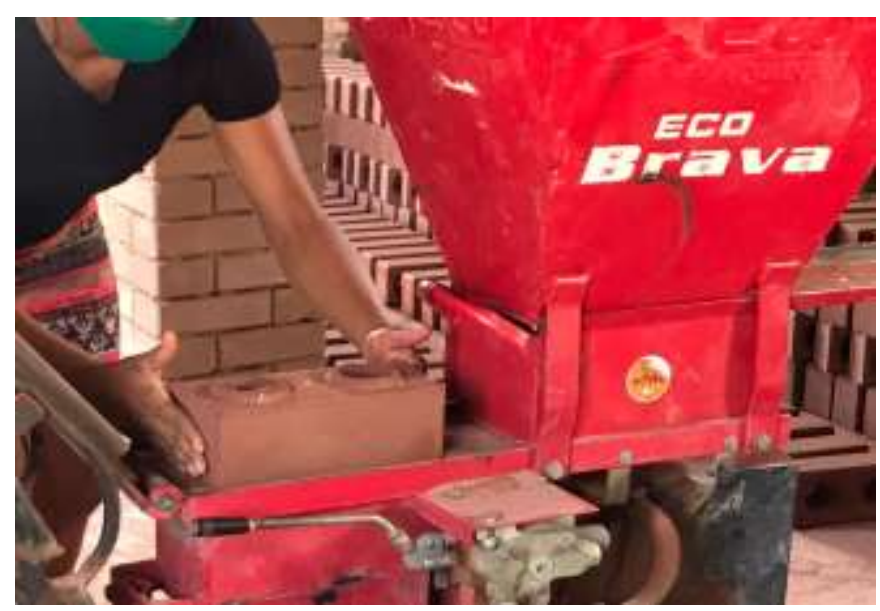

Fonte: Autor (2021).

\subsubsection{Cura}

Ainda de acordo com a ABNT NBR 10833/2012, após a moldagem (Figura 10) e durante os sete primeiros dias, os tijolos devem ser umedecidos, a fim de garantir a cura necessária. E os tijolos, podem ser utilizados após 14 dias de sua fabricação. Aos três primeiros dias de cura deve ser pulverizado água sobre os tijolos, de duas a quatro vezes por dia. E cada dia a mais de cura, o tijolo apresenta resistência maior, sendo que após vinte e oito dias a cura está completa e o bloco apresenta aproximadamente $95 \%$ da sua resistência de cálculo, sendo esse o prazo ideal para transporte e utilização (Pisani,2015).

Figura 10 - Início do processo de cura.

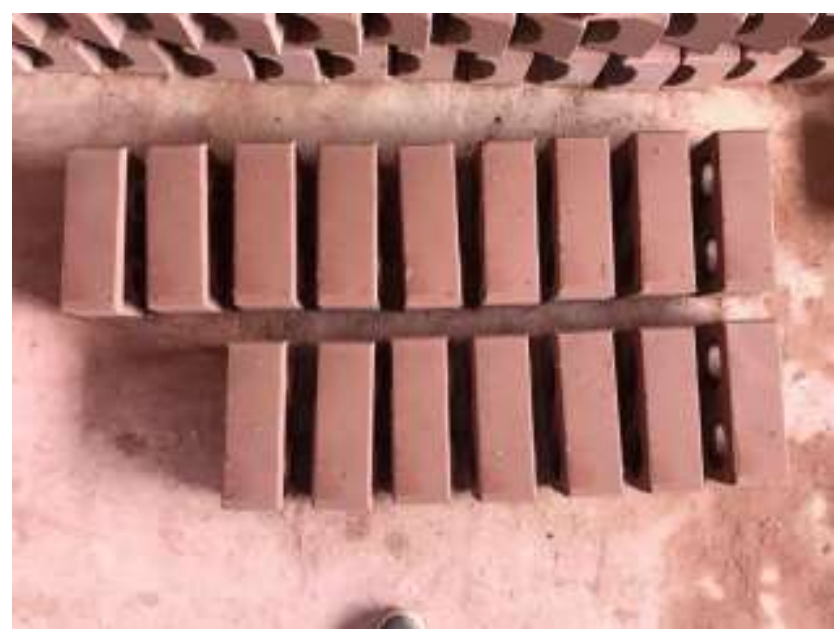

Fonte: Autor (2021).

Durante um prazo de 7 dias foram umedecidos todos os dias para possibilitar a hidratação do cimento. Ao final do período de cura, procedeu-se com a realização dos ensaios dos resistência a compressão simples e absorção de água.

\subsection{Ensaio de absorção}

Para o ensaio de absorção de água NBR 8491:2012, os blocos foram colocados em estufa, apresentada na Figura 11, com temperatura entre $105^{\circ} \mathrm{C}$ e $110^{\circ} \mathrm{C}$. E após retirados da estufa já em temperatura ambiente foram pesados secos.

Figura 11 - Estufa utilizada para o ensaio de absorção de água. 


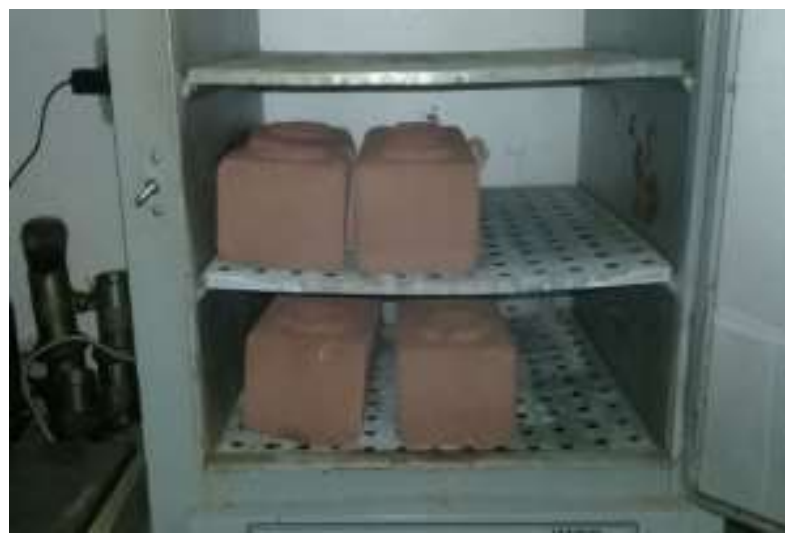

Fonte: Autor (2021).

Em seguida, foram submersos em um recipiente durante 24h, e a Figura 12 ilustra os corpos de prova submersos em água. Após sua retirada da água, foram enxugados com um pano levemente úmido e pesados, obtendo-se a massa do tijolo saturado,

Figura 12 - Corpos de prova submersos.

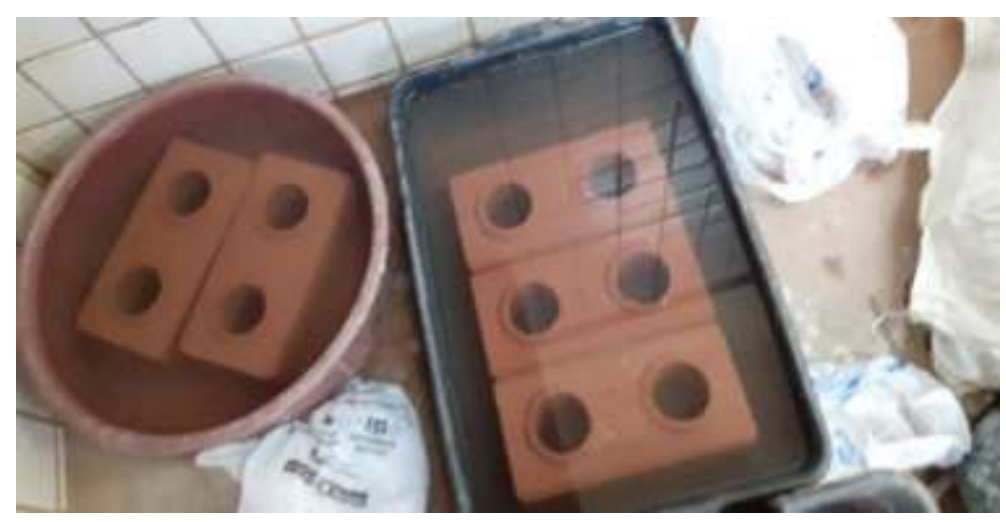

Fonte: Autor (2021).

\subsection{Compressão simples}

As amostras ensaiadas devem estar de acordo com a ABNT NBR 8492/2012, não podendo apresentar média dos valores de resistência à compressão menor do que 2,0 Mpa e nem valor individual inferior a 1,7 Mpa, com idade mínima de sete dias. O ensaio de resistência a compressão (Figura 13) foi realizado em quatro tijolos, para cada grupo de formulação ( $0 \%$, $40 \%$ e $60 \%$ ) de adição de copos descartáveis triturados.

Figura 13 - Ensaio para obtenção de resistência. 


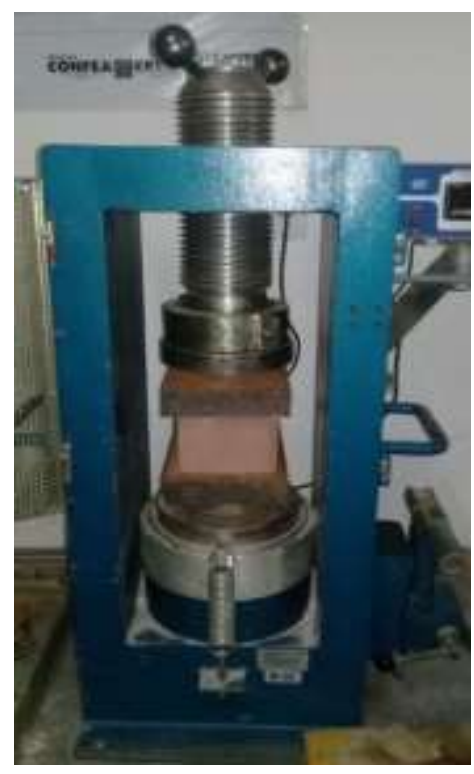

Fonte: Autor (2021).

\section{Resultados e Discussão}

\subsection{Ensaio do vidro}

Ensaio que consiste em tomar um frasco transparente colocar a amostra de solo até a metade do vidro. Adicionar duas colheres de sopa de sal e completar com água. Tampar o vidro, agitando-o vigorosamente. Deixa-lo em repouso por aproximadamente meia hora (Figura 14). Sendo que para um bom resultado o solo deve seguir as seguintes características: Solo bom: Quando argila = areia; Solo excelente: areia $>$ argila.

Figura 14 - Ensaio do vidro - Presença maior de argila.

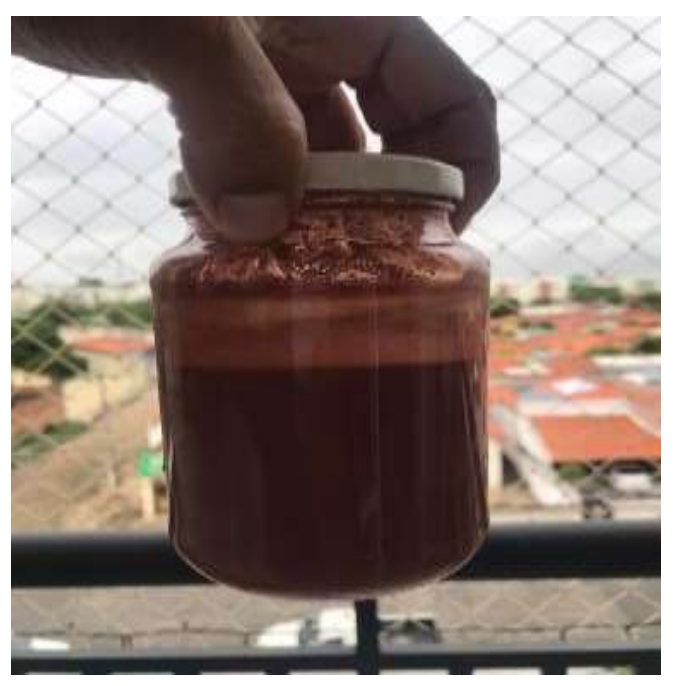

Fonte: Autor (2021) 
Research, Society and Development, v. 10, n. 14, e525101422302, 2021

(CC BY 4.0) | ISSN 2525-3409 | DOI: http://dx.doi.org/10.33448/rsd-v10i14.22302

O resultado para este ensaio do vidro: Argila = Areia que indica um solo bom, portanto não precisa ser corrigido com adição de areia. De acordo com Pinto, (2000) os índices de Atterberg são os chamados limites de plasticidade (LP) e limite de liquidez (LL). Eles se baseiam na constatação de que um solo argiloso apresenta aspectos bem distintos conforme o seu teor de umidade. Quando muito úmido se compara a líquidos, quando perde parte de sua água se torna plástico, e quando seco se torna quebradiço.

\subsection{Limite de liquidez}

O limite de liquidez da argila em estudo corresponde a 36,6\%, referente a umidade ao vigésimo quinto golpe, a amostra de solo ficou dentro do limite recomendado pela norma NBR 6459/16 que é igual ou inferior a 45\%. 
Gráfico 1 - Gráfico com resultado LL

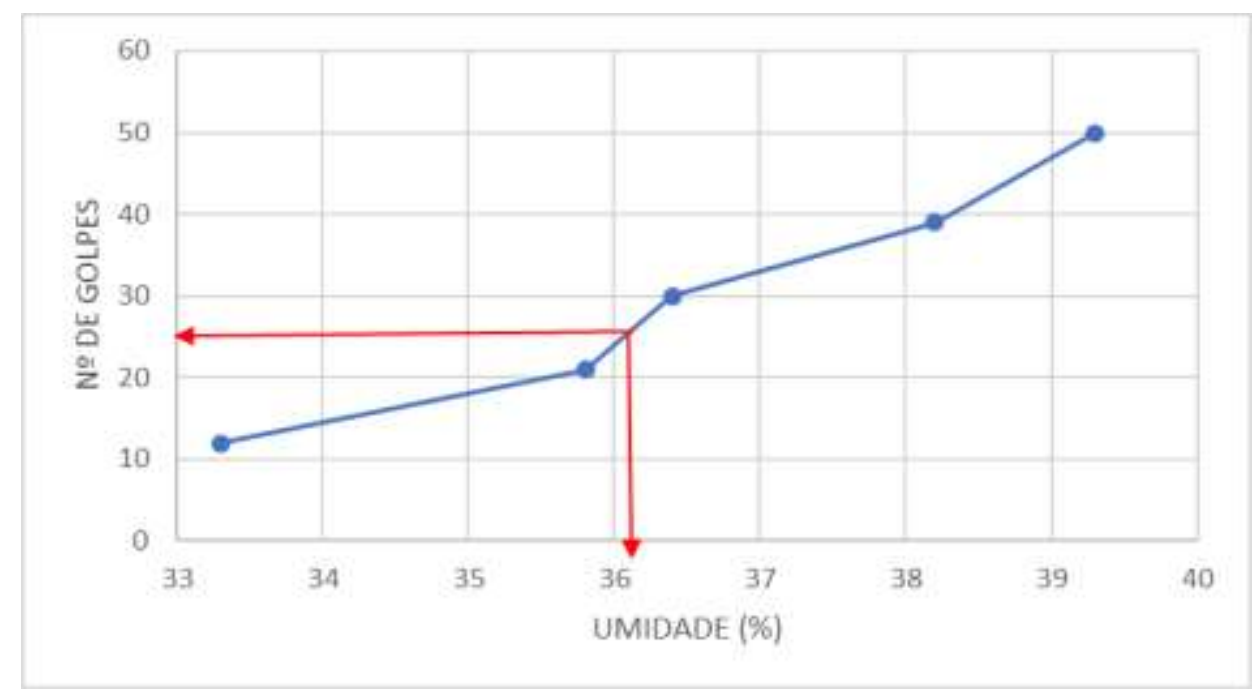

Fonte: Autor (2021).

\subsection{Limite de plasticidade}

O limite de plasticidade foi determinado a partir de amostras de solo fino e seco, utilizando uma placa de vidro e um gabarito metálico para moldagens em cilindros de 3 a 4 mm de diâmetro.

Quadro 3 - Limite de Plasticidade

\begin{tabular}{|c|c|c|c|c|c|c|}
\hline Cápsula & 01 & 06 & 08 & 09 & 10 & \multirow{7}{*}{$\begin{array}{l}\text { LL } 36,6 \% \\
\text { LP } 21,2 \% \\
\text { IP } 15,4\end{array}$} \\
\hline Peso Bruto Úmido (g) & 8,33 & 8,16 & 8,74 & 8,72 & 8,89 & \\
\hline Peso Bruto Seco $(\mathrm{g})$ & 8,17 & 8,02 & 8,55 & 8,55 & 8,72 & \\
\hline Peso da Cápsula & 7,43 & 7,33 & 7,67 & 7,74 & 7,93 & \\
\hline Peso da Água (g) & 0,16 & 0,14 & 0,19 & 0,17 & 0,17 & \\
\hline Peso do Solo Seco $(\mathrm{g})$ & 0,74 & 0,69 & 0,88 & 0,81 & 0,79 & \\
\hline Umidade (\%) & 21,6 & 20,3 & 21,6 & 21,0 & 21,5 & \\
\hline
\end{tabular}

Fonte: Autor (2021).

O limite de plasticidade (LP) é expresso pela média aritmética dos teores de umidade obtidos no ensaio, o resultado da amostra corresponde a $21,2 \%$. Isso demonstra que o solo apresenta boa plasticidade por possuir uma quantidade suficiente de finos (argila + silte) para garantir à mistura a capacidade de ser moldado no momento da fabricação do tijolo ecológico (quadro 3). O índice de plasticidade deste ensaio é determinado LL-LP é igual a 15,4\%.

\subsection{Ensaio de granulometria}

O ensaio de granulometria é fundamental importância para compreender e associar os resultados obtidos nesse trabalho ao tamanho de partícula da matéria-prima (argila) utilizada. Para o ensaio de análise granulométrica pesou-se cerca de $100 \mathrm{~g}$ de material, descontando o peso da capsula, após a pesagem a amostra foi para a estufa por um período de 24 horas, com temperatura em torno de $105^{\circ} \mathrm{C}$. 
Quadro 4 - Resultado do ensaio de granulometria.

\begin{tabular}{|c|c|c|c|c|}
\hline Peneiras & $\mathrm{mm}$ & Min & Max & Passando \\
\hline $2 "$ & 50,8 & 100 & 100 & 100,0 \\
\hline $11 / 2 "$ & 38 & 100 & 100 & 100,0 \\
\hline $1 "$ & 25,4 & 100 & 100 & 100,0 \\
\hline $3 / 4 "$ & 19 & 85 & 30 & 100,0 \\
\hline $3 / 8^{\prime \prime}$ & 9,5 & & & 100,0 \\
\hline $\mathrm{n}^{\circ} 4$ & 4,8 & & & 100,0 \\
\hline $\mathrm{n}^{\circ} 10$ & 2 & & & 100,0 \\
\hline $\mathrm{n}^{\mathbf{o}} 16$ & 1,2 & 60 & 15 & 99,9 \\
\hline $\mathrm{n}^{\mathbf{o}} 30$ & 0,6 & 45 & 10 & 99,3 \\
\hline $\mathrm{n}^{\mathbf{o}} 40$ & 0,42 & & & 97,5 \\
\hline $\mathrm{n}^{\text {o }} 50$ & 0,3 & & & 87,5 \\
\hline $\mathrm{n}^{\mathbf{o}} 100$ & 0,15 & & & 58,6 \\
\hline $\mathrm{n}^{\mathbf{o}} 200$ & 0,075 & 30 & 5 & 23,6 \\
\hline
\end{tabular}

Fonte: Autor (2021).

Nota-se que o material que passa na peneira $\mathrm{n}^{\mathrm{o}} 4(4,8 \mathrm{~mm})$ corresponde a $100 \%$ do solo e o material que passa na peneira com abertura de malha de $0,075 \mathrm{~mm}$, portanto, dentro do limite entre $10 \%$ e $50 \%$ conforme quadro 4 . Portanto, essa caracterização qualifica esse solo para a produção do tijolo ecológico, conforme critérios estabelecidos pela norma NBR 10832 (2013) apresentados na Tabela 1.

Tabela 1- Especificação do solo para produção de tijolo solo-cimento- NBR 10832/13

\begin{tabular}{cc}
\hline Características & Condições $(\%)$ \\
\hline$\%$ do solo que passa na peneira ABNT $4,8 \mathrm{~mm}$ & 100 \\
\hline$\%$ do solo que passa na peneira ABNT $0,075 \mathrm{~mm}$ & 10 a 50 \\
\hline Limite de liquidez & $\leq 45$ \\
\hline Índice de plasticidade & $\leq 18$ \\
\hline
\end{tabular}

Fonte: Adaptado de NBR 10832 (1989/2013).

\subsection{FRX da argila}

A Fluorescência de Raio X (FRX) é uma técnica que permite a identificação dos elementos constituintes no solo, como também permite observar a proporção de cada elemento na amostra (Soares,2008). A análise química da argila utilizada na pesquisa é apresentada na Tabela 2 abaixo.

Tabela 2 - Análise Química por Florescência de Raios-X dos solos.

Análise Química por Florescência de Raio-X da argila (\%)

\begin{tabular}{c|c|c|c|c}
\hline Amostra & Silício (Si) & Alumínio (Al) & Ferro (Fe) & Outros \\
\hline Argila & 85,4 & 9,83 & 4,05 & 0,72 \\
\hline
\end{tabular}

Fonte: Autor (2021). 
Conforme mostra a Tabela 2, pode-se observar que para a argila em estudo existe um alto teor de silício (85,4\%) seguido do alumínio $(9,83 \%)$, indicando que este solo é um material argiloso mais arenoso. Ensaio granulométrico de copos descartáveis triturados. O resultado do ensaio granulométrico para os copos descartáveis triturados é apresentado na Tabela 3.

Tabela 3- Resumo Granulométrico dos copos descartáveis triturados.

\begin{tabular}{c|c}
\hline Classificação & Teor retido $(\%)$ \\
\hline Pedregulho $(>4,8 \mathrm{~mm})$ & 0,00 \\
\hline Areia Grossa $(4,8 \mathrm{~mm}-2,0 \mathrm{~mm})$ & 0,42 \\
\hline Areia média $(2,0-0,42 \mathrm{~mm})$ & 65,34 \\
\hline Areia fina $(0,42-0,074 \mathrm{~mm})$ & 33,16 \\
\hline Silte+Argila $(0,074 \mathrm{~mm})$ & 0,98 \\
\hline TOTAL & 100 \\
\hline
\end{tabular}

Fonte: Autor (2021).

Analisando a Tabela 3 é possível observar que os copos descartáveis triturados apresenta um nível granulométrico próximo de areia média.

\subsection{FRX dos copos descartáveis triturados}

Para o resultado do FRX para os copos descartáveis triturados a Tabela 4 mostra que são inferiores aos padrões descritos na norma NBR 10004/04, classificando assim esse resíduo como sendo Classe II A (não inerte) podendo ser reutilizado como matéria-prima sem apresentar nenhum risco a saúde durante a produção e aplicação do produto final.

Tabela 4 - Análise Química por Florescência de Raios-x dos copos descartáveis triturados.

\begin{tabular}{c|l|l|l|l|l|l|l}
\hline \multicolumn{1}{c}{ Análise Química por Florescência de Raio-X da argila (\%) } \\
\hline Amostra & $\mathrm{CaO}$ & $\mathrm{Br}$ & $\mathrm{SiO}_{2}$ & $\mathrm{ZnO}$ & $\mathrm{Fe}_{2} \mathrm{O}_{3}$ & $\mathrm{TiO}_{2}$ & $\mathrm{~K}_{2} \mathrm{O}$ \\
\hline Copos descartáveis triturados & 84,129 & 6,305 & 3,704 & 2,612 & 0,773 & 2,271 & 0,206 \\
\hline
\end{tabular}

Fonte: Autor (2021).

\subsection{Ensaio de absorção}

Os resultados obtidos dos 3 corpos de prova para cada formulação no teste de absorção de água para determinar a porcentagem em média de absorção de água realizados na UNIFSA estão descritos na Tabela 5.

Tabela 5 - Absorção média de água aos 28 dias

\begin{tabular}{|c|c|c|c|}
\hline \multicolumn{4}{|c|}{ Absorção de água aos 28 dias } \\
\hline Composição: & $0 \%$ & $40 \%$ & $60 \%$ \\
\hline Absorção de água & 17,72 & 18,98 & 20,22 \\
\hline
\end{tabular}

Fonte: Autor (2021). 
Os resultados da Tabela 5 para absorção de água demonstraram que os corpos de prova com 40\% de adição de copos descartáveis triturados atenderam os limites estabelecidos pela norma no qual, o valor individual não pode ser superior a $22 \%$ e a média de valores não pode ser maior de $20 \%$.

\subsection{Ensaio de compressão simples}

A Tabela 6 abaixo, mostram os valores médios de resistência à compressão simples para cada grupo de formulação $(0 \%, 40 \%$ e $60 \%)$ de adição de copos descartáveis triturados.

Tabela 6 - Resultados médios dos ensaios de resistência a compressão.

\begin{tabular}{l|c|c|c}
\hline Tijolo ecológico & 7 DIAS (Mpa) & 14 DIAS(Mpa) & 28 DIAS (Mpa) \\
\hline $\begin{array}{l}\text { 0\% de copos } \\
\text { descartáveis triturados }\end{array}$ & 1,20 & 1,48 & 1,35 \\
\hline $40 \%$ de copos & 1,63 & 2,00 & 1,65 \\
descartáveis triturados & & 1,48 & 1,31 \\
\hline $\begin{array}{l}60 \% \text { de copos } \\
\text { descartáveis triturados }\end{array}$ & 1,28 & & \\
\hline
\end{tabular}

Fonte: Autor (2021).

Conforme mostra a Tabela 6 o percentual de $40 \%$ de adição de copos descartáveis triturados apresentou um melhor resultado, visto que, as outras duas amostras também atingiram valores menores de $2 \mathrm{Mpa}$ em média e enquadraram dentro dos parâmetros exigidos pela NBR 8491:2012.

\section{Conclusão}

Após a finalização deste trabalho chegou-se à conclusão de que a formulação ideal é a adição de 40\% de copos descartáveis triturados ao tijolo ecológico visto que, obteve-se melhores resultados para o ensaio de resistência a compressão e a análise de absorção de água. Portanto os tijolos produzidos com adição de copos descartáveis triturados mostraram-se que atendem os requisitos normativos e corroboram para a sustentabilidade, pois transformam materiais descartáveis novos artefatos para construção civil. Para tanto, pretende-se ainda viabilizar a realização de estudos subsequentes que possam dar continuidade a sustentabilidade ambiental, manejo e reaproveitamento adequado de materiais descartados na natureza.

\section{Sugestões para Trabalhos Futuros}

- Realizar um estudo da viabilidade econômica do uso de tijolo ecológico ou solo-cimento em com adição do reaproveitamento das fibras de copos descartáveis;

- Considerando variações ocorridas em alguns ensaios, sugerem-se diferentes condições de cura e armazenamento.

\section{Referências}

Al-Salem, S. M., Lettieri, P., \& Baeyens, J. (2009). Thermal Pyrolysis of High-Density Polyethylene (HDPE), In Proceedings of the Ninth European Gasification Conference: Clean Energy and Chemicals, Düsseldorf, Germany, 23-25 March.

Alves, F. P. V. (2018). Reciclagem e Reutilização de Materiais Poliméricos Plásticos - Rio de Janeiro: UFRJ - Escola Politécnica. 
Bandeira, F. O. (2016). Estudo da resistência ao cisalhamento de misturas de solo argiloso com resíduo de borracha de pneus. Universidade Federal da Fronteira do Sul. Chapecó.

Barsano, P. R. \& Barbosa, R. P. (2013). Meio Ambiente: Guia Prático e Didático.

Campos, I. M. (2007). Solo-cimento, solução para economia e sustentabilidade.

CEMPRE.CEMPRE REVIEW. (2015). Disponível em: http://cempre.org.br/artigo- publicacao/artigos. Acessado em: 29 out 2020.

Charles, A. H. \& Edward, M. P. (2003). Plastics Materials and Processes - A Concise Encyclopedia, Wiley-Interscience, John Wiley \& Sons, Inc, Hoboken, New Jersey.

Coelho, T.M., Castro, R., \& Gobbo J. (2001). PET containers in Brazil: Opportunities and challenges of a logistics model for post-consumer waste recycling, Resources, Conservation and Recycling, n. 55, pp. 291-299.

Corrêa, M.; \& Heemann, A. (2016). Proposta de substituição de copos plásticos descartáveis em fábrica de grande porte. MIX Sustentável, v. 2, n. 2, p. 73-79.

Cuccato, G.R.S.P. (2014). A importância da reciclagem dos plásticos e a conscientização dos alunos do ensino médio. Monografia (Especialização - Ensino de Ciências). Medianeira, PR: UTFPR, 30p.

Cunha, L. C. D. (2018). Poluição marinha por plásticos: uma questão de direito internacional. Dissertação de M.Sc., Universidade de Lisboa, Portugal.

Forlin, F. J. \& Faria, J. A. F. (2002). Considerações Sobre a Reciclagem de Embalagens Plásticas. Departamento de Tecnologia de Alimentos, FEA, UNICAMP.

Gavião, L., Barreto, M., Lima, G., Meza, L., Souza, D., \& Vieira, T. (2017). Avaliação de eficiência a partir de indicadores de sustentabilidade. Conhecimento \& Diversidade, v. 8, n. 16, p. 68-83.

Geyer, R., Jambeck, J. R., \& law, K. L. (2017). Production, use, and fate of all plastics ever made, Science Advances. v. 3, n. 7.

Gomes, R.M. (2018). Desenvolvimento de tijolo-ecológico com incorporação de resíduos de borracha de pneu. Dissertação (Mestrado em Engenharia dos Materiais) - Instituto Federal do Piauí. Campos Central, Teresina, PI, 70 p.

Gorni, A. A. (2003). Introdução aos Plásticos. Revista plástico industrial.

Matuti, B. B. \& Santana, G. P. (2019). Reutilização de resíduos de construção civil e demolição na fabricação de tijolo cerâmico - uma revisão. Scientia Amazonia, v. 8, n.1, E1-E13.

Marconi, M. D. A.; \& Lakatos, E. M. (2016). Técnicas de pesquisa: planejamento e execução de pesquisas, amostragens e técnicas de pesquisas, elaboração, análise e interpretação de dados. 3.ed. São Paulo: Atlas.

Pedroti, L. G. (2007). Estudo de conformidades em relação à ABNT de blocos cerâmicos prensados e queimados. Dissertação (Mestrado em Engenharia Civil) - Universidade Estadual do Norte Fluminense Darcy Ribeiro. Campos dos Goytacazes, RJ, 2007, 106 p.

Penha, J. R. B., Moreira, G. S. S., \& Barata, M. S. (2007). Fabricação de tijolo solo-cimento com substituição parcial do solo natural por resíduo da construção e demolição para construção de casas populares de baixo custo. In: CONGRESSO BRASILEIRO DO CONCRETO, 49, 2007, Bento Gonçalves. Anais. São Paulo: Instituto Brasileiro do Concreto, 16 p.

Pinto, L. M. (2015). Estudo de tijolos de solo cimento com adição de resíduo de construção civil. Trabalho de conclusão de curso, RS, Brasil.

Pisani, M. A. J. (2015). Um material de construção de baixo impacto ambiental: o tijolo de solo-cimento. AE ensaios, São Paulo, p. 17.

Pinto, C. S. (2000). Curso Básico de Mecânica dos Solos em 16 aulas. São Paulo, 247p.

Santos, C. (2012). Rossi dos. Estudo da utilização de rejeitos de carvão na fabricação de blocos de concreto para pavimentação em substituição ao agregado miúdo natural. 160 f. Dissertação (Mestrado em Engenharia de Minas, Metalúrgica e Materiais) - Escola de Engenharia, Universidade Federal do Rio Grande do Sul, Porto Alegre.

Santos A. F. R., Baumgart, L. N., Woiciokoski M., Tabarelli J. O., Jatzak S., \& Nicoletti V. (2009). Utilização de resíduos da construção civil em tijolos ecológicos. Trabalho Interdisciplinar, Administração da Produção II. Associação do Vale do Itajaí Mirim.

Sardella, A. (2003). Química: Série Novo Ensino Médio. 5 ed. São Paulo: Editora Ática, 191p.

Sena, R. J., Laursen, A., \& Silva, J.S. (2017). Avaliação Mecânica de Tijolo Maciço Solo-Cimento Contendo Resíduo de Pet. Ano 13, v. 10, n. 1 - Edição Especial VEREDAS MPCT.

Silva, L O., Santos, N. G., \& Savaris, W. K. (2018). Tijolos Solo-Cimento: Fabricação e Utilização em Construções que visam o Equilíbrio Ambiental. Revista Conexão Eletrônica, Três Lagoas (MS) v. 15, n. 1, p.446-455.

Stevens, E. S. (2002). Green Plastics - Na Introduction to the New Science of Biodegradable Plastics”, Princeton University Press.

Soares, R. A. L. (2008) Influência do teor de calcário no comportamento físico, mecânico e microestrutural de cerâmicas estruturais. Dissertação (Mestrado), Universidade Federal do Rio Grande do Norte. Centro de Ciências Exatas e da Terra. Programa de Pós-Graduação em Ciência e Engenharia de Materiais, 100p.

Stuart, B. H. (2004). Infrared Spectroscopy: Fundamentals and Applications. Chichester: Wiley.

Tempo, O. (2017). Brasil perde 120 bilhões por ano ao não reciclar lixo.

Zorzeto, G. (2017). Resíduos de Construção e Demolição - Problemas e Soluções. Concreta Consultoria. 